See Article page 2155.

\section{Commentary: Tying NOTSS into cardiothoracic surgery training}

\author{
Madeline L. Fryer, MMSc, ${ }^{\mathrm{a}}$ and \\ Leora B. Balsam, MD
}

The primary focus of surgical residencies has traditionally been preparing trainees with the technical skills necessary to safely perform operations. Although the ability to dissect tissue planes and control bleeding are inextricably tied to one's competency to operate, growing evidence has shown the importance of nontechnical skills (NTS) to surgical success. ${ }^{1}$ The value of interprofessional and team communication, for example, are deemed so important that they are included in the Accreditation Council for Graduate Medical Education Thoracic Surgery Milestones for trainees and have been expanded upon in the 2021 edition. ${ }^{2}$ What has lagged behind the understood importance of NTS is an effective method for teaching and evaluating them. ${ }^{3}$ The traditional view that these skills could be passively gleaned in an operating room has proven ineffective, and a variety of interventions have been explored to address this gap across a number of surgical fields. ${ }^{4}$

Kim and colleagues ${ }^{5}$ present a pilot study of a NonTechnical Skills for Surgeons (NOTSS) curriculum specifically for cardiothoracic (CT) surgery residents. Building upon the Yule group's extensive prior work with NOTSS, ${ }^{6-8}$ this study evaluated the parameters of situational awareness, decision making, communication/ teamwork, and leadership in $8 \mathrm{CT}$ surgical residency program participants during simulated vignettes. The study found that resident physicians had a statistically significant increase in overall and individual category NOTSS scores in the second set of simulations following

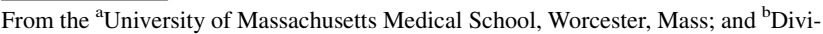
sion of Cardiac Surgery, UMass Memorial Medical Center, Worcester, Mass. Disclosures: The authors reported no conflicts of interest.

The Journal policy requires editors and reviewers to disclose conflicts of interest and to decline handling or reviewing manuscripts for which they may have a conflict of interest. The editors and reviewers of this article have no conflicts of interest.

Received for publication Feb 10, 2021; revisions received Feb 10, 2021; accepted for publication Feb 11, 2021; available ahead of print Feb 19, 2021.

Address for reprints: Leora B. Balsam, MD, Division of Cardiac Surgery, UMass Memorial Medical Center, University Campus, 55 Lake Ave N, Worcester, MA 01655 (E-mail: leora.balsam@umassmemorial.org).

J Thorac Cardiovasc Surg 2022;163:2163-4

$0022-5223 / \$ 36.00$

Copyright (c) 2021 by The American Association for Thoracic Surgery

https://doi.org/10.1016/j.jtcvs.2021.02.036
}

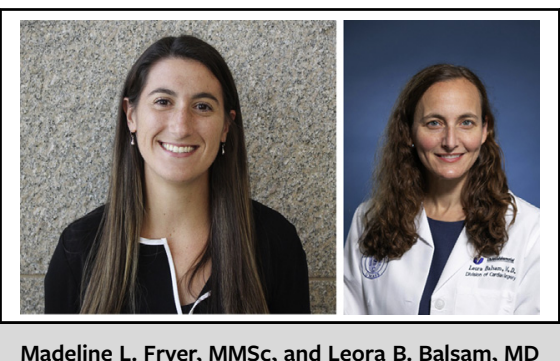

Madeline L. Fryer, MMSc, and Leora B. Balsam, MD

CENTRAL MESSAGE

Nontechnical skills are critically

important to a surgeon's success,

but standardized methods for

teaching and evaluating

nontechnical skills amongst

trainees remains a work in

progress.

the delivery of a NOTSS lecture and assigned readings. The authors also note that the intervention was easy to implement, appeared reproducible, and cost roughly $\$ 4300$ to implement per curriculum.

Although the results of this pilot study are encouraging, a number of important questions remain. This study lacked a control group and does not show that improvements in NOTSS scores were related to the interventional curriculum rather than resident physicians' increased awareness of the criteria on which they were being evaluated. This pilot study only included a small number of CT resident physicians at a single institution, which may not be representative of the variety of training paradigms approved by the Accreditation Council for Graduate Medical Education. Questions also remain surrounding the durability of this effect, particularly because other studies have suggested that NTS reach a peak and then continue to decline over the course of one's career. ${ }^{9}$ The measured outcome depended on subjective ratings, and it is unclear if changes in those NOTSS scores translate to performance in real clinical scenarios and better patient outcomes.

Overall, this work is an important step forward in establishing effective curricula for NTS in CT surgery trainees. In particular, simulation-based programs have long been touted as high-fidelity yet safe scenarios in which residents can learn. ${ }^{10}$ Although the data from this pilot study are not strong enough to trigger sweeping changes in CT residency curricula, they add to the growing notion that NTS should 
be intentionally taught to trainees. As larger, hopefully controlled studies evaluate NTS curricula, we will better understand how teamwork, situational awareness, decision making, leadership, resource management, and coping with stress lead to improved surgeon competency and patient outcomes.

\section{References}

1. Hull L, Arora S, Aggarwal R, Darzi A, Vincent C, Sevdalis N. The impact of nontechnical skills on technical performance in surgery: a systematic review. $J$ Am Coll Surg. 2012;214:214-30.

2. Beller J, Brewster L, Bull D, D'Cunha J, Edgar L, Hoffman J, et al. Thoracic Surgery Milestones. 2nd ed. Chicago, IL: Accreditation Council for Graduate Medical Education; 2020.

3. Vervoort D, Hirji S. Non-technical skills for surgeons: challenges and opportunities for cardiothoracic surgery. $J$ Thorac Dis. 2020;12:1112-4.
4. Ounounou E, Aydin A, Brunckhorst O, Khan MS, Dasgupta P, Ahmed K Nontechnical skills in surgery: a systematic review of current training modalities. J Surg Educ. 2019;76:14-24.

5. Kim JS, Hernandez RA, Smink DS, Yule S, Jackson NJ, Shemin RJ, et al. Nontechnical skills training in cardiothoracic surgery: a pilot study. $J$ Thorac Cardiovasc Surg. 2022;163:2155-62.e4.

6. Yule S, Flin R, Paterson-Brown S, Maran N. Non-technical skills for surgeons in the operating room: a review of the literature. Surgery. 2006;139: $140-9$.

7. Yule S, Flin R, Paterson-Brown S, Maran N, Rowley D. Development of a rating system for surgeons' non-technical skills. Med Educ. 2006;40:1098-104.

8. Yule S, Parker SH, Wilkinson J, McKinley A, MacDonald J, Neill A, et al. Coaching non-technical skills improves surgical residents' performance in a simulated operating room. J Surg Educ. 2015;72:1124-30.

9. Gostlow H, Marlow N, Thomas MJ, Hewett PJ, Kiermeier A, Babidge W, et al. Non-technical skills of surgical trainees and experienced surgeons. Br J Surg. 2017; 104:777-85.

10. Merry AF. Human factors and the cardiac surgical team: a role for simulation. $J$ Extra Corpor Technol. 2007;39:264-6.
See Article page 2155.

\section{Commentary: Nontechnical skills redux}

\author{
Marco A. Zenati, MD, \\ Roger D. Dias, MD, PhD, MBA, and \\ Lauren R. Kennedy-Metz, $\mathrm{PhD}^{\mathrm{a}}$
}

When applying the human factor lens, the practice of surgery can be reduced to a complex sociotechnical system, which to be successful, requires human proficiency in both technical and nontechnical skills (NTS). Appreciation of the importance of NTS in surgery is relatively recent, and education interventions focused on NTS training in surgery are scarce. Although largely still in denial, surgical

\footnotetext{
From the a Division of Cardiac Surgery, Veterans Affairs Boston Healthcare System, and Department of Surgery, Brigham and Women's Hospital, Harvard Medical School, Boston, Mass; and 'STRATUS Center for Medical Simulation, Department of Emergency Medicine, Brigham and Women's Hospital, Boston, Mass. Supported by National Institutes of Health grant R01 HL126896 to Dr Zenati.

Disclosures: The authors reported no conflicts of interest.

The Journal policy requires editors and reviewers to disclose conflicts of interest and to decline handling or reviewing manuscripts for which they may have a conflict of interest. The editors and reviewers of this article have no conflicts of interest.

Received for publication Feb 22, 2021; revisions received Feb 22, 2021; accepted for publication Feb 22, 2021; available ahead of print Feb 26, 2021.

Address for reprints: Marco A. Zenati, MD, Division of Cardiac Surgery, Veterans Affairs Boston Healthcare System, 1400 VFW Parkway, Boston, MA 02135 (E-mail: Marco_Zenati@hms.harvard.edu).

J Thorac Cardiovasc Surg 2022;163:2164-5

0022-5223/\$0.00

Published by Elsevier Inc. on behalf of The American Association for Thoracic Surgery

https://doi.org/10.1016/j.jtcvs.2021.02.072
}

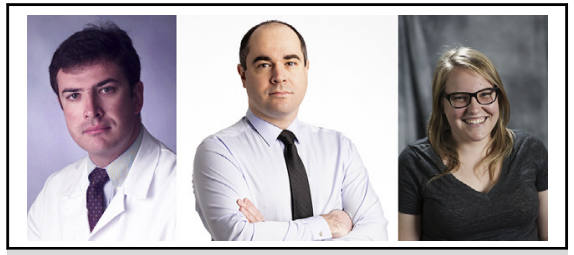

Marco A. Zenati, MD, Roger D. Dias, MD, PhD, MBA, and Lauren R. Kennedy-Metz, PhD

CENTRAL MESSAGE

A formalized nontechnical skills

for surgeons curriculum

embedded into cardiothoracic residency programs is feasible. specialties are fraught with high levels of incivility ${ }^{1}$ and psychological safety is still an aspiration. ${ }^{2}$

In 1999, Flin and colleagues ${ }^{3}$ at the University of Aberdeen in Scotland first applied safety lessons learned in the off-shore oil drilling industry (Aberdeen is the gateway harbor to the North Sea underwater oil fields) and aviation to complex health care environments, including the operating room, and developed a landmark NTS taxonomy called the Anaesthetists' Non-Technical Skills. More recently, Yule and colleagues ${ }^{4}$ developed and validated a behavioral taxonomy specifically aimed at 